\title{
Effect of Micro-scale Y Addition on the Fracture Properties of Al-Cu-Mn Alloy
}

\author{
Ting-Biao Guo ${ }^{1,2^{*}}$, Feng Zhang ${ }^{1}$, Wan-Wu Ding ${ }^{1,2}$ and Zhi Jia ${ }^{1,2}$
}

\begin{abstract}
Rare earth (RE) elements have positive effects on Al alloy, while most research is focused on microstructure and mechanical properties. As important application indices, toughness and plasticity are properties that are sensitive to alloy fracture characteristics, and few research studies have characterized the fracture properties of Al-Cu-Mn alloy on RE elements. The effect of different contents of $\mathrm{Y}$ on the fracture properties of Al-Cu-Mn alloy is investigated. T6 heat treatment (solid solution and artificial aging treatment), optical microscope (OM), scanning electron microscopy (SEM) and energy dispersive spectrometer (EDS) methods are applied to the alloy. Results showed that when Y element is present at $0.1 \%$, the section of the as-cast alloy has smaller sized dimples and the fracture mode presents ductile features. Slight changes in hardness are also observed and maintained at about $60 \mathrm{HV}$. With increasing content of the RE element $Y$ from 0.1 to $0.5 \%$, the $\theta$ phase and $\mathrm{Cu}$ atoms in the matrix were reduced and most stopped at Grain boundaries (GBs). Micro-segregation and an enriched zone of $Y$ near the GBs gradually increased. At the same time, the inter-metallic compound AlCuY is aggregated at grain junctions causing deterioration of the micro-structure and fracture properties of the alloy. After T6 treatment, the flatness of the fracture surface was lower than that of all the ascast alloy showing lots of dimples and teared edges with a significant increase in hardness. When Y content was $0.1 \%$, the strength and hardness of the alloy increased due to refinement of the grain strengthening effect. The content of Y elements segregated in the inter-dendritic zone and GBs is reduced. Plasticity and deformation compatibility also improved, making cracks difficult to form and merge with each other along adjacent grain junctions and providing an increased potential for ductile fracture. This paper proposes the addition of RE $Y$ as an effective and prospective strategy to improve the fracture properties of the Al-Cu-Mn alloy and provide a meaningful reference in terms of improving overall performance.
\end{abstract}

Keywords: Al-Cu-Mn alloy, Solid solution, Fracture toughness, Mechanical properties

\section{Introduction}

High-strength aluminum alloy has been widely used in the aerospace industry for its good comprehensive properties [1-4], however, due to the poor casting properties of the alloy, it is easy to cause segregation, shrinkage, and other defects, and the tendency to hot cracking is serious, to a certain extent, and its fracture toughness is limited. More onerous requirements are being imposed on the strength of aluminum alloy in order to meet the needs of wider application, improving the fracture toughness

\footnotetext{
*Correspondence: gtb777@163.com

${ }^{1}$ School of Materials Science and Engineering, Lanzhou University of Technology, Lanzhou 730050, China

Full list of author information is available at the end of the article
}

of the alloy, reducing its tendency to brittle fracture, and controlling catastrophic failures are important problem facing those working with such an alloy.

Fracture toughness plays an important role in determining the fracture behavior of metallic materials. Improving fracture toughness and reducing the tendency to brittle fracture are important ways to enhance the service performance of $\mathrm{Al}$ alloys. Therefore, studying fracture properties has great significance in ensuring the security and reliability of $\mathrm{Al}$ alloys.

Research has found that large initial cavity volumes can cause reduced fracture strain of pre-stretched aluminum alloy plates [5]. Cold-rolling can avoid oxide inclusions and enhance its mechanical properties, in particular its fracture toughness [6]. Recrystallization has been shown 
to decrease stress corrosion cracking and inter-granular fractures of $\mathrm{Al}-\mathrm{Zn}-\mathrm{Mg}-\mathrm{Cu}$ alloy [7-9], but these researchers could not find an effective mechanism with which to improve the fracture toughness of $\mathrm{Al}$ alloy.

It is found that the addition of RE elements has significant effects improving the fracture toughness. They can reduce the solidification temperature range, decrease the tendency to hot cracking and improve the strength of the alloy. Among those advantages, RE elements can effectively refine the grain structure of the alloy, make the strength and hardness of the alloy increase significantly, and increase the fracture toughness thereof. At the same time, the distribution of segregation phases can be changed, and the stress concentration and crack initiation can be reduced [10-12]. More importantly, because of its active chemical properties, adding a certain amount of rare earth elements can reduce the amount of hydrogen gas and adsorb other impurities, purify the alloy in melt form, slag and shrinkage defect counts are reduced, the microstructural organization becomes more compact, and the tendency to hot cracking is also reduced.

The corrosion resistance of $\mathrm{Al}-\mathrm{Mg}-\mathrm{Cu}-\mathrm{Sc}-\mathrm{Zr}$ alloy can be improved by the introduction of Sc and $\mathrm{Zr}$ which cause discontinuous precipitation along GBs [13]. REdoped Al-brass has good corrosion resistance which positively impacts the fracture properties of $\mathrm{Al}-\mathrm{Cu}-\mathrm{Mn}$ alloy [14]. Al-12Si-4Cu-2Ni-0.8Mg alloy, upon addition of $\mathrm{Sr}$, shows a brittle fracture mode [15]. The addition of RE elements has become one of the most important methods by which to improve the fracture properties.

In particular, adding trace amounts of yttrium can reduce the porosity and the mechanical properties of $\mathrm{Al}$ alloys can be improved. $\mathrm{Sn}-1.0 \mathrm{Ag}-0.5 \mathrm{Cu}$, when alloyed with $\mathrm{Y}$, exhibited excellent fracture strength $[16,17] . \mathrm{Mg}-\mathrm{Zn}-\mathrm{Y}-\mathrm{Zr}$, when alloyed with a Y content of $2 \%$, had the largest fatigue strength and cracks were hard to initiate [18]. It can also refine grains by formation of $\mathrm{Al}_{2} \mathrm{Y}$ thus improving the strength and resisting plastic fracture failures [19]. Li found that tensile properties of an $\mathrm{Al}$ alloy, with added $\mathrm{Y}$, were improved and a dimple-like mechanism was responsible for ductile fractures therein [20]. These researchers demonstrate that $Y$ has positive benefits arising from the fact that it refines grains, and increases the strength and fracture toughness of $\mathrm{Al}$ alloy. However, research into RE Y and its effects on the fracture properties of $\mathrm{Al}-\mathrm{Cu}-\mathrm{Mn}$ alloy are rare, and the mechanism change of fracture toughness is not clear. In this case, the study of RE $\mathrm{Y}$ in the fracture of $\mathrm{Al}-\mathrm{Cu}-\mathrm{Mn}$ alloy is of great value. In this study, we investigated the effect of Y addition on the fracture properties, and elucidated the fracture mechanism of $\mathrm{Al}-\mathrm{Mn}-\mathrm{Cu}$ alloy.

\section{Experimental Section}

The master-slave control is widely employed in the robot manipulation. In most cases, the joystick or the keyboard is the routine input device for the robot master-slave control system. $\mathrm{Al}-\mathrm{Cu}-\mathrm{Mn}$ alloy was investigated as the base material and its chemical composition are shown in Table 1. Table 2 presents the additional amounts of intermediate Al-Y alloy. The Master alloy was weighed in proportion and put into a crucible resistance furnace. The furnace was heated to $730{ }^{\circ} \mathrm{C}$ and $0.5 \% \mathrm{C}_{2} \mathrm{Cl}_{6}$ was added with a bell jar to refine the base matter. After slag skimming and thermal insulation for 10 minutes, the temperature was raised to $750{ }^{\circ} \mathrm{C}$ and the intermediate alloy $\mathrm{Al}-\mathrm{Y}$ was added with bell jars and stirred uniformly. The mechanical properties of the alloy specimens were casted when temperature dropped to $710{ }^{\circ} \mathrm{C}$. A T6 treatment $\left(540{ }^{\circ} \mathrm{C} \times 10 \mathrm{~h}\right.$ solid solution and $150{ }^{\circ} \mathrm{C} \times 8 \mathrm{~h}$ artificial aging treatment) process was used. Tensile specimens were processed and corroded for $10 \mathrm{~s}$ after polishing with 99.5\% $\mathrm{H}_{2} \mathrm{O}+0.5 \%$ HF liquid. The macro-structures of the fracture specimens were observed using a MEF$3 \mathrm{OM}$ and micro-structures were tested using a JSM5600LVSEM. The tensile test was conducted using an AG-10TA universal electronic tensile testing machine and the alloy Vickers hardness was measured.

\begin{tabular}{llcl}
$\begin{array}{l}\text { Table } 2 \text { Addition } \begin{array}{c}\text { amounts } \\
\text { and intermediate alloy }\end{array} \\
\text { Furnace no. }\end{array}$ & Al-Cu-Mn (g) & Al-Y (g) & $\begin{array}{l}\text { Y element } \\
\text { mass fraction } \\
(\%)\end{array}$ \\
\hline 1 & 1 & 0 & 0 \\
2 & 3.33 & 30 & 0.1 \\
3 & 6.67 & 60 & 0.2 \\
4 & 10 & 90 & 0.3 \\
5 & 13.3 & 120 & 0.4 \\
6 & 16.67 & 150 & 0.5 \\
\hline
\end{tabular}

Table 1 Chemical composition of Al-Cu-Mn alloy (mass fraction, \%)

\begin{tabular}{lllllllllll}
\hline Elements & $\mathbf{C u}$ & $\mathbf{M n}$ & $\mathbf{T i}$ & $\mathbf{C d}$ & $\mathbf{V}$ & $\mathbf{Z r}$ & $\mathbf{A l}$ \\
\hline Contents & 5 & 0.4 & 0.2 & 0.2 & 0.25 & 0.2 & Bal. \\
\hline
\end{tabular}




\section{Results and Discussion}

\subsection{Fracture Characteristics of the As-cast Alloy}

The macro-fracture structure of the as-cast alloy with the addition of different $Y$ contents is presented in Figure $1(\mathrm{a})-(\mathrm{d})$. It can be seen from Figure 1 that the cavity contents in Figure 1(b) are less than those shown in Figure 1(a) and (c). There is little change in macro fracture morphology of the studied alloys with increasing amounts of $\mathrm{Y}$.

To demonstrate fracture characteristics, Figure 2(a)(e) respectively show the fracture morphologies of ascast alloy under different conditions. From Figure 2(a), it can be seen that small numbers of apertures appear on the whole surface morphology observed at $\times 35$ magnification. White and mesh structures and small sized dimples can also be seen in Figure 2(b) (showed at $\times 200$ ) with very few apertures emerging in the local section. Figure 2(c) shows that large particle phases appear on the cross section observed at $\times 500$ magnification. Their surfaces are smooth with gaps existing in the adjacent positions between the particles. Further observation in Figure 2(d) at $\times 2000$ magnification shows the shape and arrangement of metal particles between large compounds are irregular with parts of them distributed as the shape of layer. At the same time, the distance of gaps between particles increases. The distance is found to further increase and the particles are shown as breakage parts in Figure 2(e) which was observed at $\times 5000$ magnification.

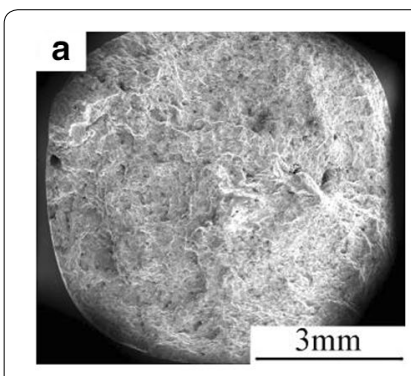

0

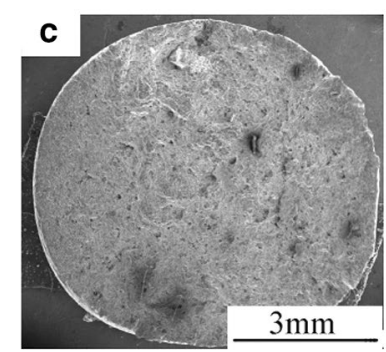

$0.3 \%$

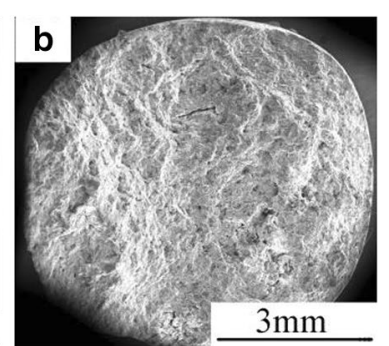

$0.1 \%$

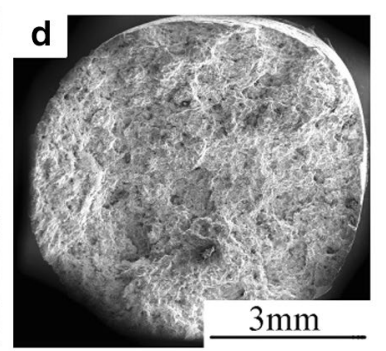

$0.5 \%$
Figure 1 Macro-fracture structures of as-cast alloy with the addition of different $Y$ contents
According to the results above, the micro-structure of the as-cast $\mathrm{Al}-\mathrm{Cu}-\mathrm{Mn}$ alloy is relatively loose bits of aperture formed on fracture sections during the casting and cooling process which relates to the properties of the studied alloy. A large number of small and shallow dimples indicate the tendency of ductile fractures of ascast alloy. However, the smooth and large particles on the cross section are incoherently arranged and lamellar compounds and the particle gaps emerged at the junction of large particles. $\mathrm{Al}-\mathrm{Cu}-\mathrm{Mn}$ alloy presents brittle fractures in those weak positions under additional tensile stress due to the poor degree of inter-granular connections. Meanwhile, gaps between large particles are also equivalent to micro-crack sources. Once stress is generated, micro-cracks will converge to grow and connect the main cracks which are blocked at GBs and consequently the as-cast alloy shows brittle fractures.

\subsection{Fracture Characteristics of the Alloy with T6 Heat Treatment}

Figure 3(a)-(d) shows the macro-fracture structure of heat treated alloy with the addition of different $\mathrm{Y}$ contents. The cavities gradually enlarge when the content of $\mathrm{Y}$ is $0.1 \%$. In addition, the alloy with the addition of $0.3 \%$ $\mathrm{Y}$ exhibits finer fracture morphology flatness than that of the as-cast alloy (shown in Figure 3(c)).

Figure 4(a)-(e) respectively shows the fracture morphologies of the alloy under different multiples after T6 heat treatment. Figure 4(a) shows that the quantities of apertures are smaller than the cast status observed at $\times 35$. Figure 2(b) observed at $\times 200$, shows that aperture numbers further reduce with the increase of white mesh structures and small equiaxed dimples. Figure 4(c) at $\times 500$ magnification shows that the number of apertures declines sharply whilst the number of white mesh structures also increases. Not only does the size of the dimples enlarge but also the new particle compounds appear at the bottom of them which form as a result of the matrix and secondary phases (or other inclusions) being separated from each other when the alloy is subjected to a pulling force. The new particles at the bottom of dimples can therefore be seen as $\mathrm{Al}_{2} \mathrm{Cu}$ or inclusions. Figure $4(\mathrm{~d})$ at $\times 2000$ shows that the size of dimples becomes larger and at the same time new broken phases can be found. In Figure 4(e), cracking phenomenon appears at local edges of the dimples and new particles disappear which was observed at $\times 5000$ magnification. Taking the series of variations after $\mathrm{T} 6$ heat treatment into consideration, it is shown that $\mathrm{Al}-\mathrm{Cu}-\mathrm{Mn}$ alloy contained amounts of $\mathrm{Y}$ and consequently presented characteristic of ductile fractures.

From the data, it was interpreted that the diffusion velocity of solute atoms is accelerated during heat 


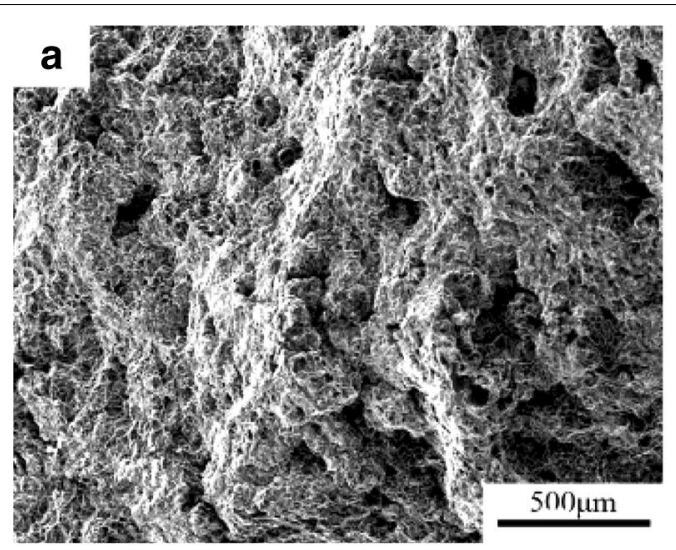

$\times 35$

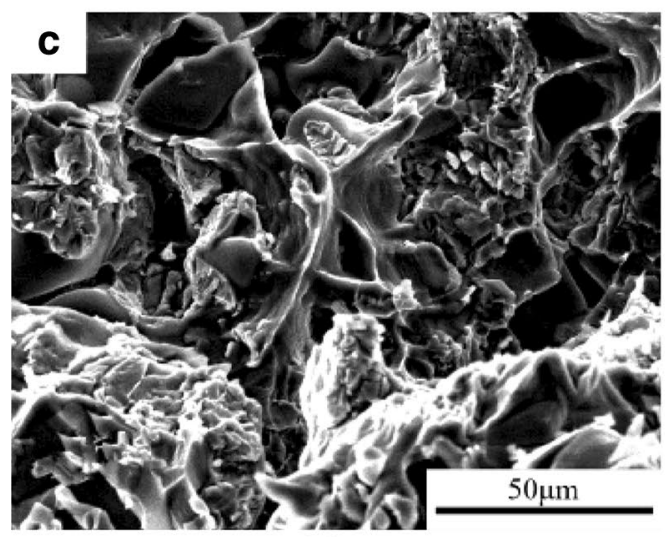

$\times 500$

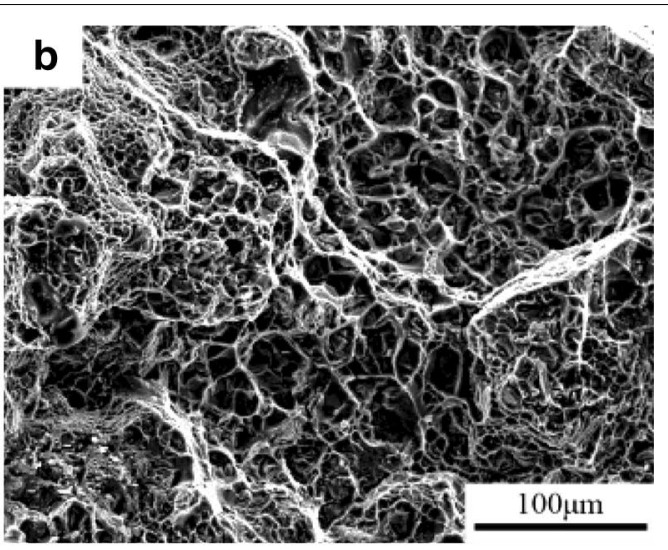

$\times 200$
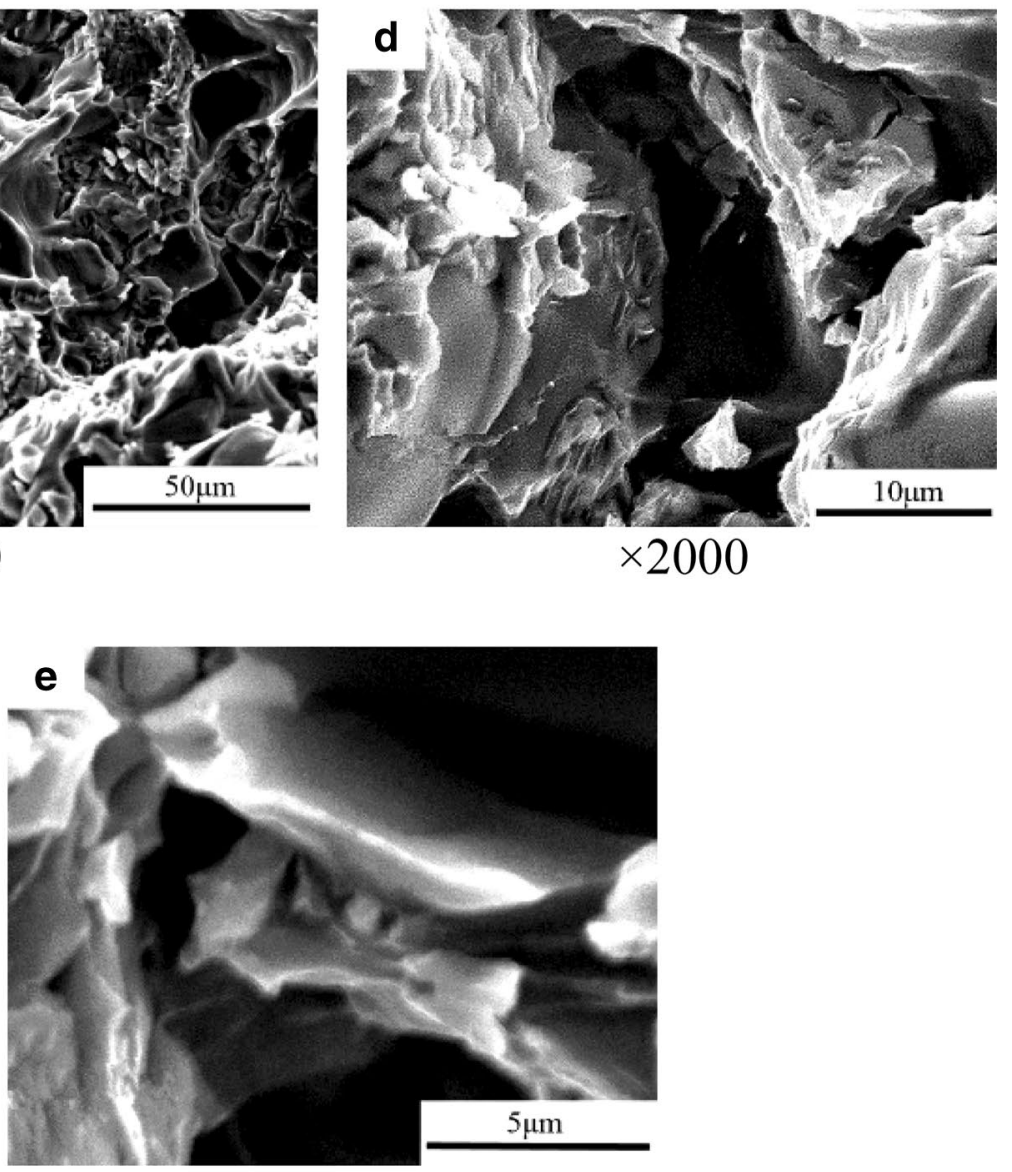

$\times 5000$

Figure 2 Fracture morphology of the as-cast alloy under different multiples

treatment which leads to casting defects such as shrinkage holes and the removal of shrinkage porosities which eliminates micro-segregation. Composition and microstructures tend to be homogeneously distributed due to the long time and high temperature during the process of solution treatment. At the same time, the ability of $Y$ to diffuse into matrix improves and the dispersion strengthening effect of the $\theta$ phase enhances improvements in the 


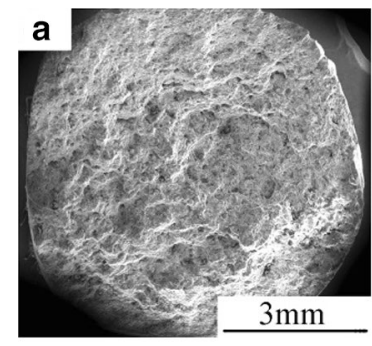

0

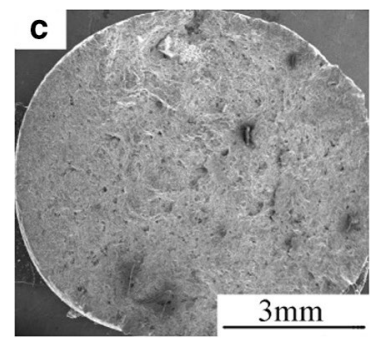

$0.3 \%$

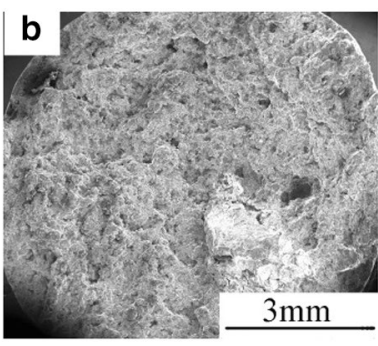

$0.1 \%$

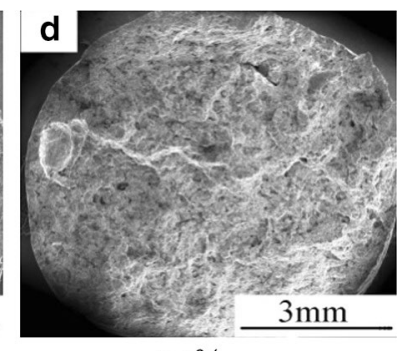

$0.5 \%$
Figure 3 Macro-fracture structure of heat-treated alloy with the addition of different $Y$ contents

matrix strength. In the absence of $\mathrm{Y}$, other segregation tends to be more homogeneously distributed on GBs. Furthermore, the degree of connection between grains is strengthened and the continuity of phases distributed on GBs and deformation compatibility between the various grains are also reinforced. Under the action of tensile stress, cracks cannot be born in GBs of the studied alloy. If stress reaches the limit point of tensile strength, plastic deformation occurs and dimples are formed due to the matrix and second phases separating from each other. Microscopic holes will form and grow up to connect with each other at the interface of inclusions of the secondary phases. Meanwhile, as the deformation progresses, the size of dimples becomes deeper and larger and its edges are cracked as well, eventually white mesh tearing ridges are formed as shown in the figures below suggesting that trans-granular fractures are present.

Figure 5(a)-(d) respectively shows the images of ascast alloy with different $Y$ contents observed by SEM. As shown in Figure 5(a), GBs are uniform and the width is mainly homogeneous. Most of the $\theta$ phases distributed on GBs are a mesh style whereas others are hindered at multiple grain junctions. In Figure 5(b), GBs become wider and the number of white reticular structures on them increases with the addition of $0.1 \%$ Y. From Figure 5(c) and (d) it can be seen that reticular structures are reduced and tend to dissolve and break gradually with $\theta$ phase segregates at multiple grain junctions.

Based on these data, Y may diffuse into the matrix material because of its high activity coefficient at $0.1 \%$ addition, as it has the ability to fill in positions where defects are present. In this case, the partial paths for $\mathrm{Cu}$ to rush into the matrix are occupied and $\mathrm{Cu}$ atoms and dislocations are blocked at GBs. This strengthens GBs under the action of blocked $\mathrm{Cu}$ and undiffused Y. As a result, moving resistance of dislocation increases and the tensile strength of GBs is improved and so the broadened boundaries appear with the addition of Y. As the percentage of $\mathrm{Y}$ increases, the contents of undiffused $\mathrm{Y}$ at boundaries increase whilst simultaneously the inter-metallic compound $\mathrm{AlCuY}$ is formed and distributed at boundaries that obstructed $\mathrm{Cu}$ moving to matrix. The reticular $\theta$ phase is also reduced. This phenomenon results in a weakening effect of the matrix on absorbing $\mathrm{Cu}$. Furthermore, the inter-metallic compound AlCuY segregated at multiple grain junctions causes micro segregation, which is a disadvantage of the properties of $\mathrm{Al}-\mathrm{Cu}-\mathrm{Mn}$ alloy. If the addition of RE $\mathrm{Y}$ increases continuously, tensile strength and fracture toughness would decrease and the tendency of ductile fractures also decrease.

\subsection{Hardness}

The hardness of as-cast and T6 heat treated alloy with different contents of Y was determined. Samples were placed on the supporting plate and moved to the pressure needle by operating handles that made the sample level contact with the hardness pressure foot. When the pressure needle stopped moving, hardness values were read in $1+0.1 \mathrm{~s}$. Four values were tested at different places which where at least $6 \mathrm{~mm}$ from the edge of the samples (shown as Figure 6(a)) and averages were calculated as shown in Figure 6(b).

The curve indicates that the hardness value of as-cast alloy without $\mathrm{Y}$ is around $65 \mathrm{HV}$ and shows the decline characteristic with as the $\mathrm{Y}$ content increases. The value tends to be stable at $50 \mathrm{HV}$ when the addition increases to $0.2 \mathrm{wt} \%$. After that moment, the hardness rises slowly with $0.3 \mathrm{wt} \%$ addition and shows a decreasing tendency. After T6 heat treatment, the hardness value reaches $122 \mathrm{HV}$ without $\mathrm{Y}$. When $\mathrm{Y}$ increases from 0.2 to 0.3 $w t \%$, the value increases to $181 \mathrm{HV}$ sharply. With a further increase of $\mathrm{Y}$ content, the hardness value is initially reduced to $130 \mathrm{HV}$ and subsequently increases. Ultimately, the hardness reaches a stable value of $142 \mathrm{HV}$ but in general the hardness of the studied alloy with RE Y is higher than that without Y.

Integrated analysis showed that distortion of a crystal lattice and system with higher internal energy appears when $\mathrm{Y}$ is diffused into matrix because of its large radius. As a result, solute atoms and the undiffused $Y$ tend to be distributed at the front of solid-liquid interfaces leading to composition undercooling, so crystallization numbers increase and grain size decreases. 


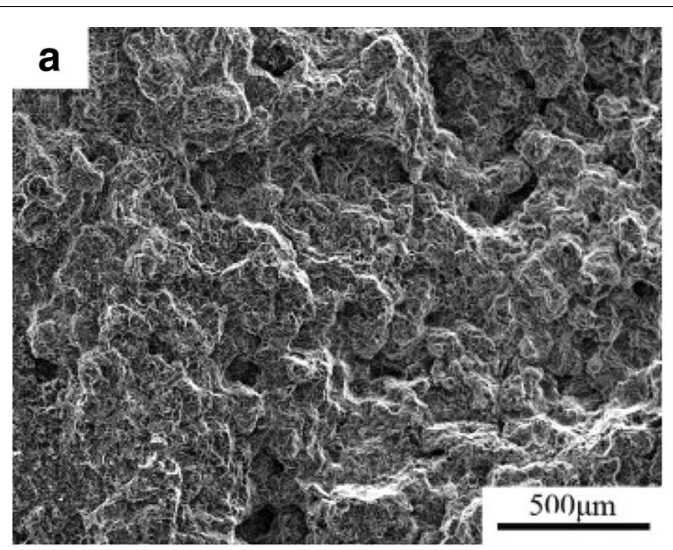

$\times 35$

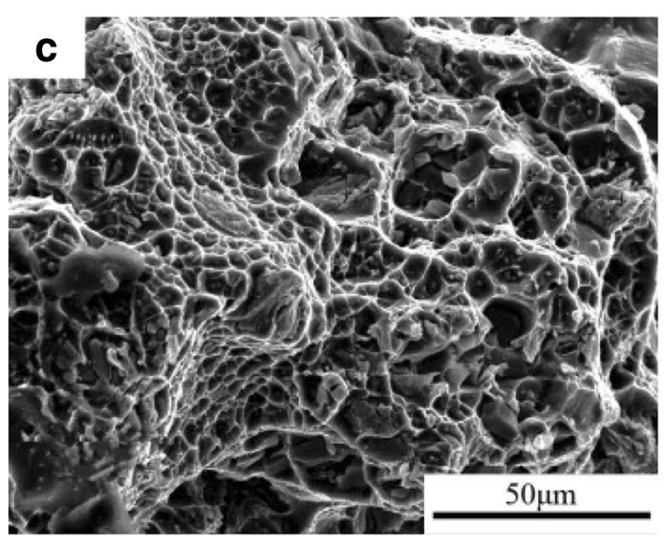

$\times 500$

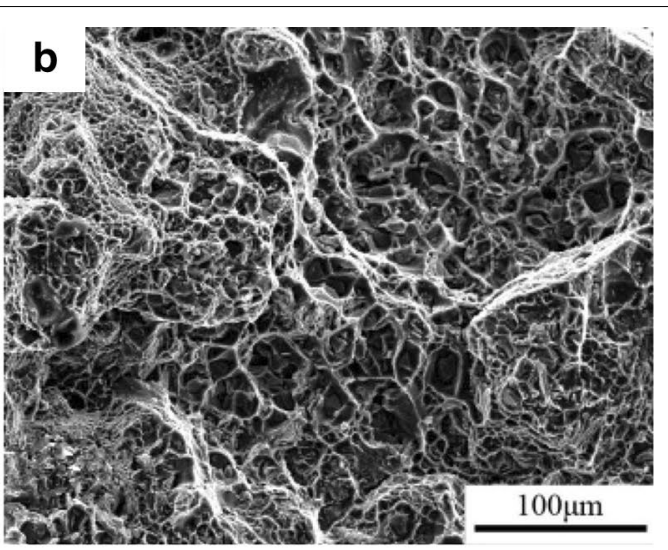

$\times 200$

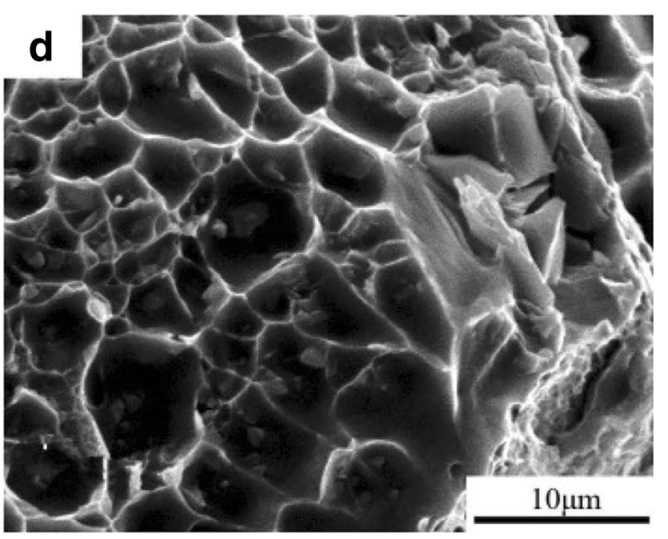

$\times 2000$

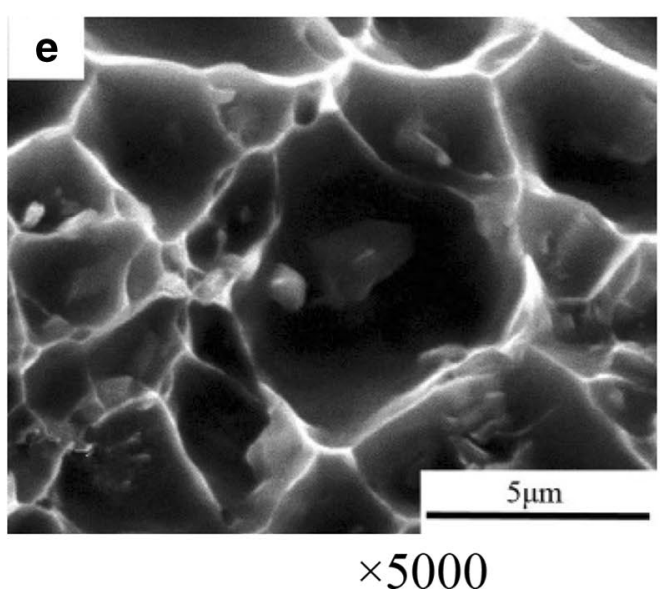

Figure 4 Fracture morphology of T6 treated alloy under different multiples

With the increase of $\mathrm{Y}$ additions, the concentration of solutes also increases which causes the equilibrium crystallization temperature to decrease. In addition, with the undercooling decreased, lots of refined grains are pushed and restricted by each other to progress and grow upwards. At the end of the solidification process, grains tend to be tightly distributed and so mechanical properties such as hardness, strength and toughness 


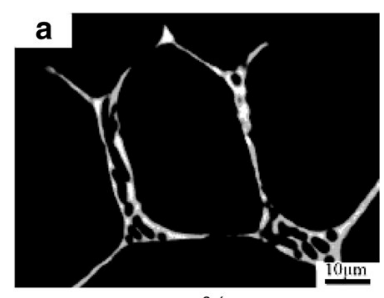

$0 \%$

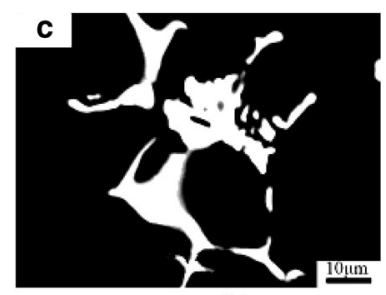

$0.3 \%$

Figure 5 SEM images of the studied alloy with different $Y$ contents

a

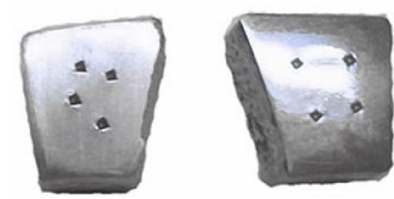

Sample hardness of different positions

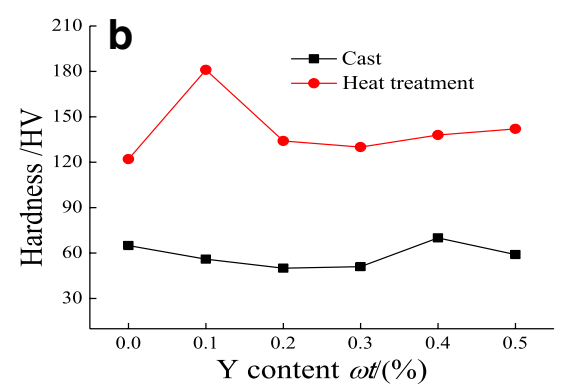

Effect of different $\mathrm{Y}$ content on hardness of Al-Cu-Mn alloy Figure 6 Effects of changes in hardness

are enhanced due to fine grain strengthening. It can be interpreted that refined grains with more boundaries act as obstacles to the propagation of cracks and so as to enhance fracture toughness. In this case, the strength of the matrix and hardness reach a stable status, whereas stress concentration increases and GBs are divided by agglomeration phases that lead to the continuity of boundaries to decrease. The bond strength between grains and tensile strength is reduced which causes the deformation compatibility between grains and deterioration of fracture toughness.

\section{Fracture Property Analysis}

\subsection{Fracture Mechanism of As-cast Alloy with the Addition} of $Y$ Elements

Analysis showed that the toughness of the as-cast alloy is reduced by inhomogeneous micro-structure and internal stress. The brittle fractures of the alloy are manifested by cracks that extended along GBs. The GB strength is weakened by undissolved AlCuY and the remainder of $\mathrm{Y}$ and precipitation of the $\theta$ phase at multiple grain junctions. These positions with poor properties can be an important source for the development of alloy cracks. The action of external stress results in alloy being undrawn along GBs as the result of the microporous structures. Stress concentration can also be caused easily by the heterogeneous distribution of the inter-metallic compound $\mathrm{AlCuY}$ which reduces fracture toughness and restricts the capability of plastic deformation as the alloy is embrittled. The level of plastic deformation for an as-cast alloy with $\mathrm{Y}$ is reduced and presents an embrittlement fracture pattern under external stress.

\subsection{Fracture Mechanism of Alloy with Y Elements after Heat Treatment}

The inter-metallic compound $\mathrm{AlCuY}$ and $\theta$ phase aggregated on the multiple grain junctions diffuse slightly and dimples with different sizes and shapes appear. Dimples and compound particles with cracks emerge in the process of plastic deformation in some micro-areas. With heat treatment, the dimples gradually become deeper and bigger indicating enhancement of fracture toughness and an increased tendency of ductile fractures.

This change can results from the fracture mode of alloy after T6 heat treatment transforms from brittle to ductile fracturing and can be explained by the following possible reasons:

(1) With the solution treatment, the diffusion velocity of the most solute atoms on the GBs rises so that the moving resistance for dislocations is weakened. The solubility of the solute atoms increases and some of the $\mathrm{Y}$ element is dissolved into matrix diffuses sufficiently and becomes uniformly distributed, the micro-structure and mechanical properties are therefore improved. Undiffused $\mathrm{Y}$ and the inter-metallic compound $\mathrm{AlCuY}$ aggregated on GBs spreads to low concentration zones causing a high concentration gradient induced by great decrease of segregation and agglomeration. The distribution of solute composition is also homogenous. The relationship between 
adjacent grains is closer, and in this case deformation compatibility increases.

(2) Stress relaxation generated through casting holes, micro-apertures and shrinkage holes during the process of solution treatment enhances alloy plasticity. As the treatment carried on, the micro-apertures are filled with diffused solute atoms and integrated with each other. As a result, the relative density increases and secondary phases tend to be distributed closely with the crystalline grains of matrix. In this case, plastic deformation occurs and dimples emerge due to secondary phases from matrix micro-structures under the action of external stress. Cracks propagate and the $\mathrm{Al}-\mathrm{Cu}-\mathrm{Mn}$ alloy breaks through the ductile fracture mechanism.

\subsection{EDS Analysis}

The EDS test results of $\mathrm{Al}-\mathrm{Cu}-\mathrm{Mn}$ alloy are shown in Figure 7. The overall distribution of alloy with RE Y is shown in Figure $7(\mathrm{a})$. Figure $7(\mathrm{~b})-(\mathrm{e})$ show the distribution of $\mathrm{Al}, \mathrm{Cu}, \mathrm{Ag}$ and $\mathrm{Y}$ elements respectively in the matrix. It was found that $\mathrm{Al}$ elements present a more
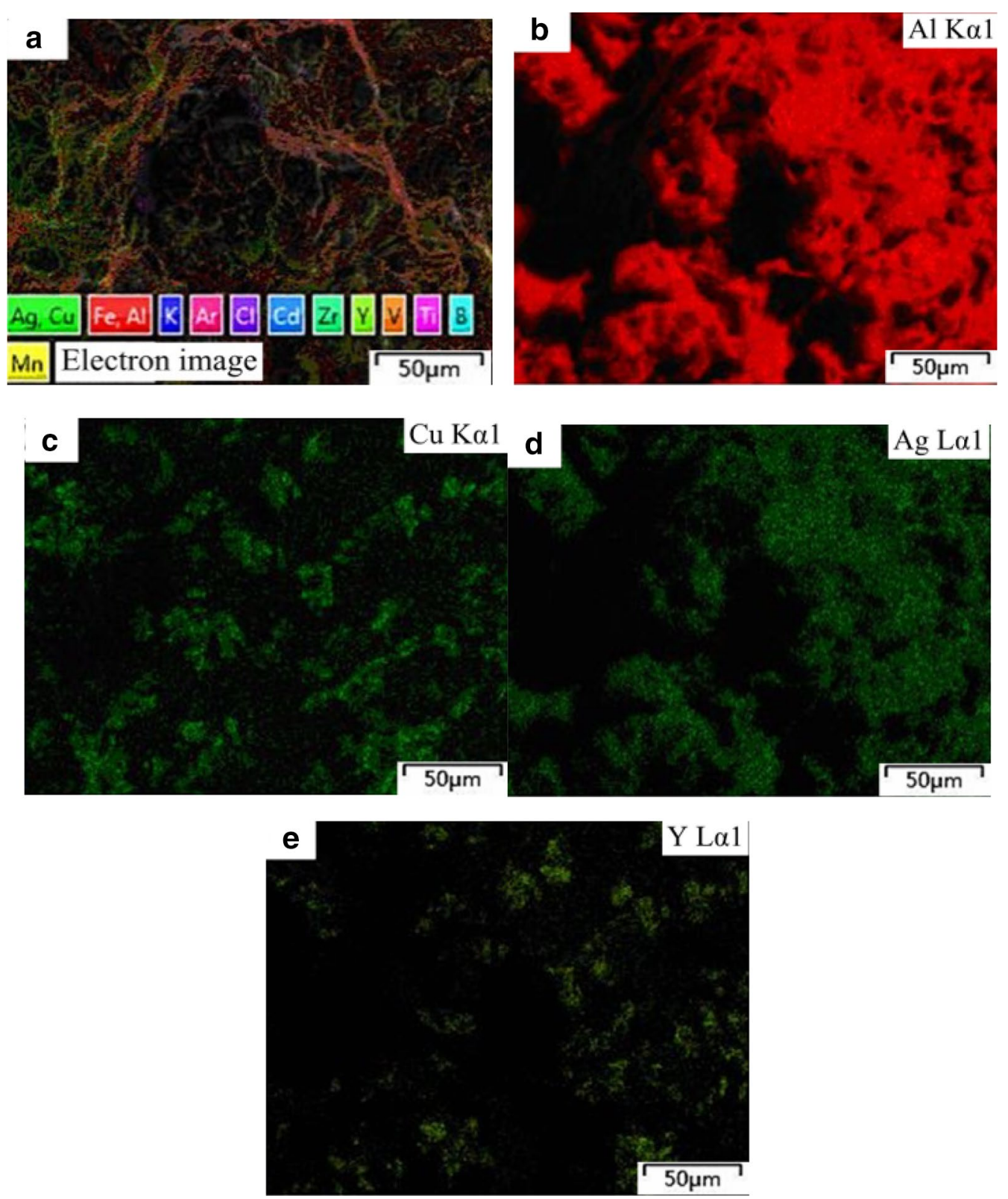

Figure 7 a EDS images of alloy, b-e element distributions 
uniform distribution than $\mathrm{Cu}, \mathrm{Ag}$ and $\mathrm{Y}$, which show the phenomenon of segregation. This can be explained as the crystal lattice and stress are created when RE Y elements burst into the matrix causing the energy of alloy system to increase. The distribution and diffusion of $Y$ elements in the matrix are not well-proportioned and so segregation occurs in local areas of matrix. In response to different temperatures and solute atoms, the continuity of matrix micro-structure is destroyed and the deformation compatibility is reduced as the tendency of brittle fracture increases.

To analyze the distribution of RE $\mathrm{Y}$ in the matrix, micro-structures with the addition of $0.3 \% \mathrm{Y}$ were tested using the EDS method and the results are shown in Figure 8 . The concentration of $\mathrm{Y}$ element in the alloy matrix (shown as Figure 8(f)) and $\theta$ phase (shown as Figure 8(c)) has the same values of $0.2 \%$ when $0.3 \%$ of $\mathrm{Y}$ is added. Analysis considered that the $\theta$ phase distributed at GBs mainly came from segregation. The most unfound RE $\mathrm{Y}$ indicates that fewer amounts of $\mathrm{Y}$ get into the matrix meaning that the most segregates or agglomerates in the internal alloy develop in areas with rich RE Y elements.

It is difficult for the $\mathrm{Y}$ element to diffuse into matrix and distribute in a well-proportioned because of its large sizes and it can form segregated regions easily around the parts of matrix. The micro-structure of the alloy is not uniform so the toughness is weakened. At the same time, the inter-metallic compound $\mathrm{AlCuY}$ produced from the $\mathrm{Y}$ and $\theta$ phase is distributed at multiple grain junctions. As a result, the contents of $Y$ in the matrix are reduced after heat treatment. AlCuY remains at grain junctions and additional $\theta$ phase worsen the connection ability of interfaces between secondary phases and matrix. Microcracks form on the surfaces of the secondary phase particles due to the stress concentration caused by elastic lattice. Once cracks develop, they can extend rapidly to easily cause brittle fractures. In addition, the inter-metallic compound $\mathrm{AlCuY}$ is distributed on GBs heterogeneously and the density of alloy micro-structure weakens. More importantly, the fracture toughness is also shown to deteriorate.

\subsection{Analysis of Fracture Properties of the Alloy}

From integrated analysis, the normal direction of the fracture surface is in conformity with the drawing direction of the alloy without $\mathrm{Y}$, indicating that brittle fractures appear. When the $\mathrm{Y}$ content is $0.1 \%$, the fine grain begins to be strengthened so that the comprehensive mechanical properties increase and the alloy tends to be cracked through ductile fractures. With the increase of $Y$, small quantities of $Y$ get dissolved in matrix merely
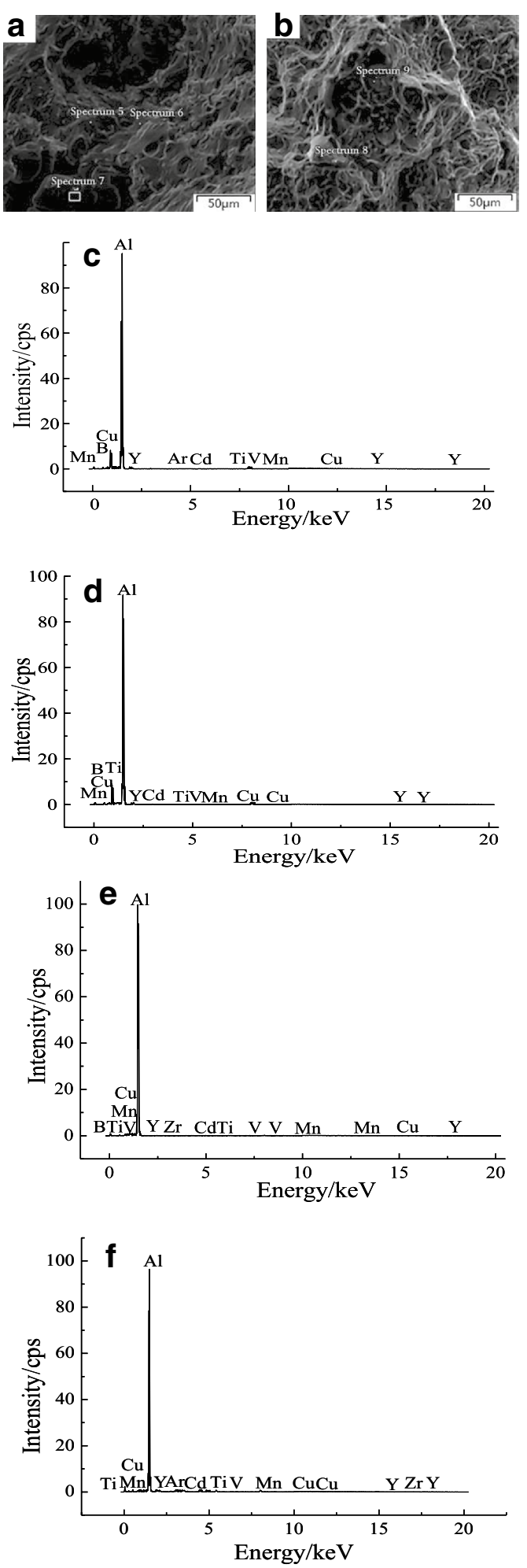

Figure $\mathbf{8}$ a, $\mathbf{b}$ Images of alloys, c-f local EDS images of the studied alloy 
because of its unique properties such as large radius, high activation energy in diffusion and the limited solubility of solid solution, however most $Y$ aggregates on GBs that stop $\mathrm{Cu}$ from diffusing and dissolving to $(\alpha-\mathrm{Al})$ phase. Therefore, with the dispersion strengthening of $\mathrm{Cu}$ interior of the matrix, the strength of matrix and boundaries is weakened.

Conversely, the difference of $\mathrm{Al}-\mathrm{Cu}-\mathrm{Mn}$ alloy plasticity between the matrix and $\mathrm{Al}_{2} \mathrm{Cu}$ is large as the matrix plasticity is higher than $\mathrm{Al}_{2} \mathrm{Cu}$, so the deformation compatibility will degrade during the plastic deformation process. This means that dislocation motions are prevented by particles $\left(\mathrm{Al}_{2} \mathrm{Cu}\right.$ or inclusions) during plastic deformation in matrix areas around particles. Obstacles are aggravated due to the addition of $\mathrm{Y}$ and dislocations nearby those particles with dislocation rings remain at the end of the dislocation motion. With continuous deformation, dislocations pile-up in groups between particles and matrix interfaces along with increased stress concentration. At the same time, dislocations are constantly prolonged, initiating and making micro-cracks grow. In addition, the contents of the inter-metallic compound $\mathrm{Al}_{2} \mathrm{Cu}$ reduces due to the formation of $\mathrm{AlCuY}$. The concentration of $\mathrm{Cu}$ on GBs improves the capability of $\mathrm{Al}_{2} \mathrm{Cu}$ to hinder dislocation enhancement. The increased stress concentration forces cracks to form, grow and connect with each other rapidly and so the alloy presents ductile fractures.

The rest of the RE Y element and inter-metallic compound $\mathrm{AlCuY}$ aggregates at GBs to greatly increase micro-segregation. These changes reduce the continuity of micro-structures. Tensile strength and ability of plastic deformation are also weakened. In this case, plastic deformation can be improved by RE Y only in a certain ranges $(<0.3 \%)$. As a consequence of RE Y addition, tensile strength increases and the alloy is then damaged by ductile fracture. Furthermore, the service life of $\mathrm{Al}-\mathrm{Cu}-$ $\mathrm{Mn}$ alloy is prolonged. If the content of RE element $\mathrm{Y}$ is added continuously, instead of being uniformly distributed, it stays at GBs as the style of segregation groups that relationship of each grain reduces. At the same time, tensile strength and plastic deformation ability are inhibited as micro-cracks begin to rapidly form. The tendency of ductile fracture shows a downward transformation. In addition, one-way stress is exerted showing that stress direction of the studied specimens is unidirectional. The effect of deformation in other directions on fracture properties remains to be fully determined and should be explored by further investigation.

\section{Conclusions}

(1) The hardness of the as-cast alloy with micro-scale $\mathrm{Y}(0.1 \%-0.5 \%)$ changes slightly and is maintained at about $60 \mathrm{HV}$. Apertures and inter-metallic compound particle $\mathrm{AlCuY}$ appear on fracture surfaces. Dimples are also shown on the fracture surfaces of the as-cast alloy indicating that the alloy with Y presents ductile fracture characteristics.

(2) When the $\mathrm{Y}$ content is $0.1 \%$, solute $\mathrm{Cu}$ atoms and undiffused RE Y are stopped at GBs making it difficult for dislocations and GBs to move. This makes grains get refined, and fracture toughness increased. With the increase of $Y$ content, the tendency of the ductile fracture style can decrease.

(3) After T6 treatment, micro-segregation is greatly reduced, while hardness and fracture toughness increase. The fracture properties of the studied alloy are improved and prompted to present ductile fracture.

\section{Authors' Contributions}

TBG was in charge of the whole trial; FZ wrote the manuscript; WWD and ZJ assisted with sampling and laboratory analyses. All authors read and approved the final manuscript.

\section{Author Details}

${ }^{1}$ School of Materials Science and Engineering, Lanzhou University of Technology, Lanzhou 730050, China. ${ }^{2}$ Key Laboratory of Nonferrous Alloys and Processing of Ministry of Education, Lanzhou 730050, China.

\section{Authors' Information}

Ting-Biao Guo, born in 1974, is currently an associate professor at School of Materials Science and Engineering and State Key Laboratory of Advanced Processing and Recycling of Non-ferrous Metals, Lanzhou University of Technology, China. His research interests include casting micro-structure controls, material micro-structures and properties and the preparation of bulk ultra-fine grained materials.

Feng Zhang, born in 1991, is a graduate student at School of Materials Science and Engineering, Lanzhou University of Technology, China. His research interests lie in micro-structures and mechanical properties of Al alloys.

Wan-Wu Ding, born in 1979, is currently an associate professor at School of Materials Science and Engineering and State Key Laboratory of Advanced Processing and Recycling of Non-ferrous Metals, Lanzhou University of Technology, China. His research interests lie in micro-structures and mechanical properties of Al alloys.

Zhi Jia, born in 1985, is currently an associate professor at School of Materials Science and Engineering and State Key Laboratory of Advanced Processing and Recycling of Non-ferrous Metals, Lanzhou University of Technology, China. His research interests lie in micro-structures and mechanical properties of $\mathrm{Al}$ alloys.

\section{Competing Interests}

The authors declare that they have no competing interests.

\section{Funding}

Supported by Gansu Provincial Science and Technology Major Special Program Foundation of China (Grant No. 1302GKDA015) and State Key Laboratory 
of Advanced Processing and Recycling of Non-ferrous Metals Open Foundation of Lanzhou University of Technology of China (Grant No. SKL1303).

\section{Publisher's Note}

Springer Nature remains neutral with regard to jurisdictional claims in published maps and institutional affiliations.

Received: 22 February 2017 Accepted: 13 September 2018 Published online: 21 September 2018

\section{References}

[1] XY Liu, Q L Pan, X L Zhang, et al. Creep behavior and microstructural evolution of deformed Al-Cu-Mg-Ag heat resistant alloy. Materials Science \& Engineering A, 2014, 599(5): 160-165.

[2] S Bai, Z Liu, X Zhou, et al. Stress-induced thickening of $\Omega$ phase in Al-Cu$\mathrm{Mg}$ alloys containing various Ag additions. Materials Science \& Engineering C, 2014, 589: 89-96.

[3] S Bai, X Zhou, Z Liu, et al. Effects of Ag variations on the microstructures and mechanical properties of $\mathrm{Al}-\mathrm{Cu}-\mathrm{Mg}$ alloys at elevated temperatures. Materials Science \& Engineering A, 2014, 611(611): 69-76.

[4] Y Kurata, H Yokota, T Suzuki. Development of Al-alloy coating for advanced nuclear systems using lead alloys. Journal of Engineering for Gas Turbines and Power, 2012, 134(6): 1-7.

[5] H F Ding, C C Zhu, CX Song. Study on pretension fracture of aluminum alloy thick plate with defect. Journal of Mechanical Engineering, 2016, 52(12): 1-7. (in Chinese)

[6] VS Aigbodion, C U Atuanya. Effect of cold deformation on the microstructure and properties of Al-Cu-Mg/Bean pod ash nano-particles composites. Journal of Alloys \& Compounds, 2015, 647(7): 728-733.

[7] S Chen, K Chen, P Dong, et al. Effect of recrystallization and heat treatment on strength and SCC of an Al-Zn-Mg-Cu alloy. Journal of Alloys \& Compounds, 2013, 581(18): 705-709.

[8] H C Fang, H Chao, K H Chen. Effect of recrystallization on intergranular fracture and corrosion of Al-Zn-Mg-Cu-Zr alloy. Journal of Alloys \& Compounds, 2015, 622(11): 166-173.
[9] HC Fang, F H Luo, K H Chen. Effect of intermetallic phases and recrystallization on the corrosion and fracture behavior of an $\mathrm{Al}-\mathrm{Zn}-\mathrm{Mg}-\mathrm{Cu}-\mathrm{Zr}-$ Yb-Cr alloy. Materials Science \& Engineering A, 2016, 684: 480-490.

[10] ZW Chen, M J Tang, K Zhao. Effect of rare earth samarium addition on the kinetics of precipitation in Al-Cu-Mn casting alloy. International Journal of Minerals, Metallurgy and Materials, 2014, 21 (2): 155-161.

[11] F Meng, Z Wang, Y Zhao, et al. Microstructures and properties evolution of Al-Cu-Mn alloy with addition of vanadium. Metals - Open Access Metallurgy Journal, 2016, 7(1): 1-12.

[12] B A Chen, G Liu, R H Wang, et al. Effect of interfacial solute segregation on ductile fracture of Al-Cu-Sc alloys. Acta Materialia, 2013, 61(5): 1676-1690.

[13] Y Shi, Q Pan, M Li, et al. Effect of Sc and Zr additions on corrosion behaviour of Al-Zn-Mg-Cu alloys. Journal of Alloys \& Compounds, 2014, 612(41): $42-50$.

[14] G Y Lin, YX Zhou, J H Zeng, et al. Influence of rare earth elements on corrosion behavior of Al-brass in marine water. Journal of Rare Earths, 2011, 29(7): 638-644.

[15] Y Sui, Q Wang, G Wang, et al. Effects of Sr content on the microstructure and mechanical properties of cast Al-12Si-4Cu-2Ni-0.8Mg alloys. Journal of Alloys \& Compounds, 2015, 622: 572-579.

[16] G Hua, H Ahmadi, M Nouri, et al. Positive effect of yttrium on the reduction of pores in cast Al alloy. Materials Chemistry \& Physics, 2015, 149-150: 140-144.

[17] H Choi, W D Kaplan, H Choe. Effect of Yttrium on the fracture strength of the Sn-1.0Ag-0.5Cu solder joints. Journal of Electronic Materials, 2016, 45(7): 1-4.

[18] D K Xu, E H Han. Effect of Yttrium content on the ultra-high cycle fatigue behavior of Mg-Zn-Y-Zr alloys. Materials Science Forum, 2015, 816(8): 333-336.

[19] HT Son, Y H Kim, T S Kim, et al. Mechanical properties and fracture behaviors of the as-extruded Mg-5Al-3Ca alloys containing Yttrium at elevated temperature. Journal of Nanoscience \& Nanotechnology, 2016, 16(2): 1806-1809.

[20] B Li, HWang, J Jie, et al. Effects of yttrium and heat treatment on the microstructure and tensile properties of Al- $7.5 \mathrm{Si}-0.5 \mathrm{Mg}$ alloy. Materials \& Design, 2011, 32(3): 1617-1622.

\section{Submit your manuscript to a SpringerOpen ${ }^{\circ}$ journal and benefit from:}

- Convenient online submission

- Rigorous peer review

- Open access: articles freely available online

- High visibility within the field

- Retaining the copyright to your article

Submit your next manuscript at $\boldsymbol{\nabla}$ springeropen.com 